\title{
EFFECTS OF CADMIUM ON THE ACTIVE TRANSPORT OF SODIUM BY THE ABDOMINAL SKIN OF A BULLFROG (RANA CATESBEIANA)
}

\author{
Hideo Hayashi, Makoto TAKada, and Akira Arita \\ Department of Physiology, Saitama Medical School, \\ Moroyama, Iruma-gun, Saitama, 350-04 Japan
}

\begin{abstract}
Effects of $\mathrm{Cd}$ on the active transport of $\mathrm{Na}$ in $\mathrm{SO}_{4}$-Ringer's solution on the abdominal skin of a bullfrog (Rana catesbeiana) were investigated. The short circuit current (SCC), potential difference (PD), and $\mathrm{Na}$ flux were determined. The skin resistance $\left(R_{M}\right)$, the electromotive force of active $\mathrm{Na}$ transport $\left(E_{\mathrm{Na}}\right)$, and the resistance to the active $\mathrm{Na}$ current $\left(R_{\mathrm{Na}}\right)$ were calculated from the measured data. The application of $\mathrm{Cd}$ to the epidermal side at $2 \mathrm{~mm}$ was more effective in increasing $\mathrm{SCC}$ than that to the dermal side at the same concentration. The time course of changes in SCC induced by Cd were classified into three types: (I) a simple increase in SCC during Cd application, (II) an early decrease followed by an increase in SCC, and (III) a decrease in SCC except for a small increase in the initial short period. Type I response was observed in the majority of cases (about two-thirds). Types II and III were observed in 7 and 32 percent of 28 cases, respectively. The Cd-induced changes in SCC were analyzed on the basis of changes in $E_{\mathrm{Na}}$ and $R_{\mathrm{Na}}$. In Type I, the increase in SCC was due to a remarkable decrease in $R_{\mathrm{Na}}$ without an appreciable change in $E_{\mathrm{Na}}\left(\because \mathrm{SCC}=E_{\mathrm{Na}} / R_{\mathrm{Na}}\right)$. In Types II and III, the changes in SCC in the early and the later stages could be explained by the differences in the extents to which $E_{\mathrm{Na}}$ and $R_{\mathrm{Na}}$ decreased. The experimental and calculated ratios of $\mathrm{PD}_{\mathrm{Cd}}$ to $\mathrm{PD}_{\text {control }}$ in these stages were in good agreement with each other.
\end{abstract}

Frog skin has long been regarded as an excellent material for the study of active transport of $\mathrm{Na}$ because of the easiness of flux measurements and electrical studies (Ussing, 1949). The effects of various metal ions, such as Ca (CURRAN and Gill, 1962), Cu (ZAdunaisky et al., 1963; Ferreira, 1970), La (MartinezPalomo et al., 1971) and Cd (Stymans and Borghgraef, 1969; Hillyard and GonICK, 1976), have been studied in the frog skin to elucidate the mechanism of

Received for publication March 14, 1977

林 秀生, 高田真理, 有田 彰 
the active transport on $\mathrm{Na}$. We are especially interested in the effect of $\mathrm{Cd}$, because it has been known to be antagonistic to calcium which plays some important roles in regulation of normal physiological functions in various preparations such as contraction of cardiac muscle and neurotransmitter release from autonomic nerve endings (HAYASHI and HORIUCHI, 1971; HAYASHI and TAKAYAMA, 1977). The active transport by frog skin was decreased by Ca (CURRAN and Gill, 1962), therefore, we examined Cd effects on the frog skin in order to find out whether $\mathrm{Cd}$ might exert an effect opposite to $\mathrm{Ca}$, i.e., does it increase the $\mathrm{Na}$ active transport or not.

The effects of $\mathrm{Cd}$ on the frog skin have been tested by other investigators (Stymans and Borghgraef, 1969; Hillyard and Gonick, 1976); however, their results do not seem to be consistent with respect to Cd-induced changes in the short circuit current (SCC) and the skin resistance $\left(R_{M}\right)$. We examined Cd effects under simplified conditions, namely, all $\mathrm{Cl}$ ions in Ringer's solution were replaced by more impermeable anions, $\mathrm{SO}_{4}$ and gluconate, so that we could exclude the probable effects on passive and the possible active transport of anions.

Preliminary accounts of this work were given elsewhere (HAYASHI et al., 1974).

\section{MATERIALS AND METHODS}

The abdominal skin of a bullfrog (Rana catesbeiana) of both sexes were used between December 1973 and May 1974. The experimental animals, which were captured around the Chiba district, were supplied by the "Supply Center of Biological Materials in Japan." The frogs were kept at room temperature in a bath for a week or two without feeding. The water level was adjusted to just above the abdomen of the animals.

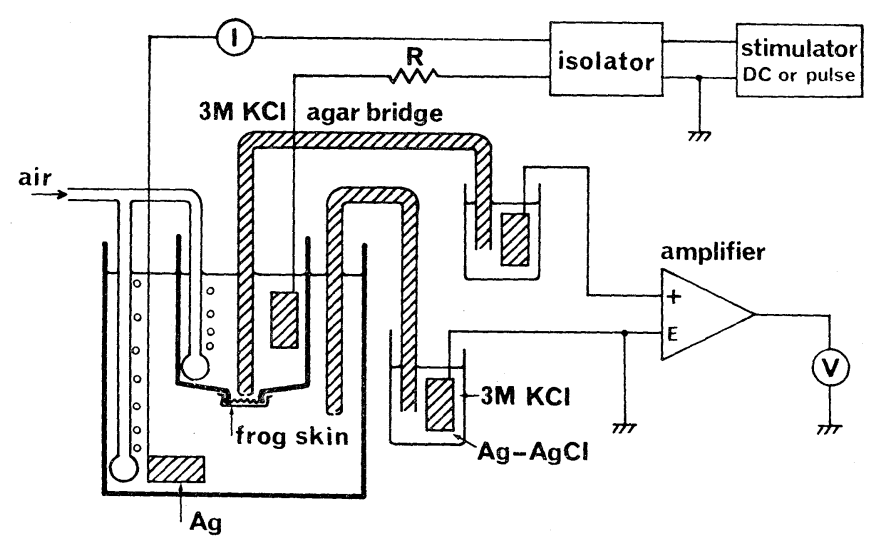

Fig. 1. Diagram of an apparatus (type A) for measuring the potential difference and the short circuit current of abdominal frog skin. The preparation was mounted on a tip of a vertical glass cannula. I: microammeter, $\mathrm{V} \cdot$ millivoltmeter. 


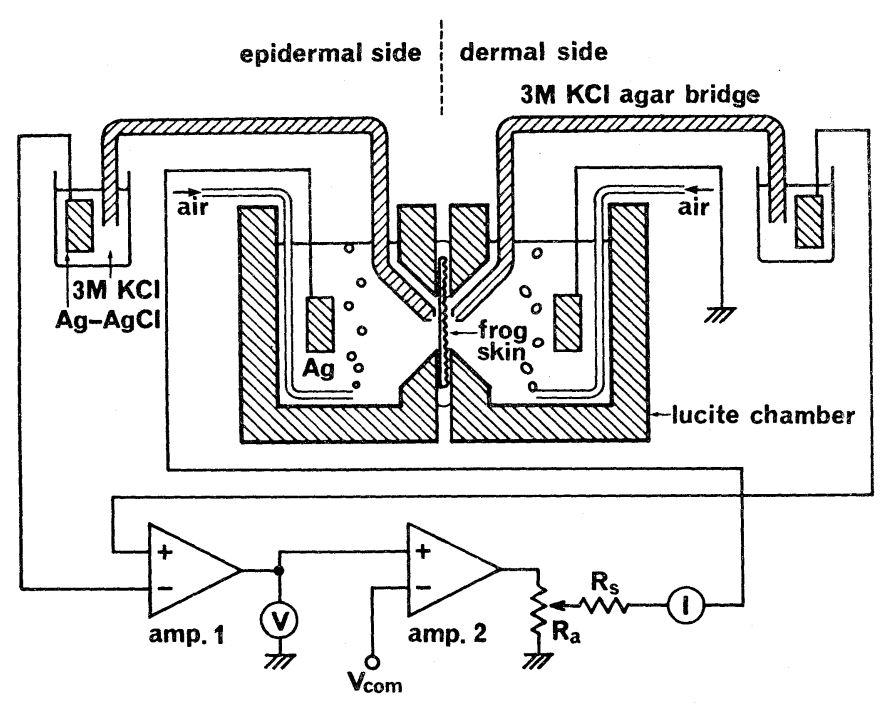

Fig. 2. Diagram of an apparatus (type B) for determining $\mathrm{Na}$ flux under the short circuited condition in frog skin. The preparation was mounted between Ussing-type lucite chambers. $V_{\text {com }}$ : ground potential.

The frogs were anesthetized with intrathecal injection of $0.5 \mathrm{ml}$ urethane solution $(0.25 \mathrm{~g} / \mathrm{ml})$. The abdominal skin was removed by dissection and mounted either on the tip of a glass cannula (A-type apparatus, Fig. 1) or between the Ussing-type lucite chambers (B-type apparatus, Fig. 2). A-type apparatus was used for measuring the potential difference (PD) and the short circuit current (SCC) of frog skin, and B-type apparatus was used for determining $\mathrm{Na}$ flux in addition to measurements of PD and SCC.

The PD of the skin was measured (dermal side positive) at room temperature through a pair of salt bridge electrodes $(3 \mathrm{M} \mathrm{KCl}, 2 \%$ agar $-3 \mathrm{M} \mathrm{KCl}-\mathrm{Ag}-\mathrm{AgCl}$ plate), a DC amplifier (ARITA and HAYASHI, 1973), and a millivoltmeter (YEW 2051-05). The asymmetry potential between the tips of the electrodes was usually less than $1 \mathrm{mV}$.

The current was applied across the skin through a pair of silver electrodes. In the experiments with the A-type apparatus, SCC was determined by adjusting the PD to zero manually (Ussing and ZERAHN, 1951). The current was supplied from a constant current device, i.e., a high resistance, a microammeter (YEW 2011-6), an isolator and a pulse generator (Nihon Kohden MSE-JT and MSE-40). In the experiments with the B-type apparatus, SCC was regulated automatically by using a feedback amplifier (voltage clamp method). The gains of two DC amplifiers were both $40 \mathrm{~dB}$. The command signal of the control amplifier $\left(V_{\text {com }}\right)$ was maintained at zero (ground potential). The data of the SCC were expressed as $\mu \mathrm{A} / \mathrm{cm}^{2}$. The exposed skin areas were $0.79 \mathrm{~cm}^{2}$ for A-type experiment, and 
$4.9 \mathrm{~cm}^{2}$ for B-type experiment.

The skin resistance $\left(R_{M}\right)$ was calculated by using the following equation: $R_{M}=\mathrm{PD} / \mathrm{SCC}\left(\mathrm{k} \Omega \cdot \mathrm{cm}^{2}\right)$. The change in $\mathrm{PD}$ was shown to be directly proportional to the applied current ranging from zero to SCC.

Both sides of the skin preparation were soaked in aerated Ringer's solution whose hydrostatic pressure difference upon epidermal and dermal surfaces was adjusted to zero.

Most of the experiments were carried out in $\mathrm{SO}_{4}$-Ringer's solution $\left(\mathrm{Na}_{2} \mathrm{SO}_{4}\right.$ $55 \mathrm{~mm}, \mathrm{~K}_{2} \mathrm{SO}_{4} 1 \mathrm{~mm}$, Ca gluconate $1 \mathrm{~mm}$, glucose $10 \mathrm{~mm}$, sucrose $60 \mathrm{~mm}$, and Tris- $\mathrm{SO}_{4}$ buffer $10 \mathrm{~mm}, \mathrm{pH}$ 7.2). In a few preliminary experiments, Cl-Ringer's solution (HAYASHI and HoRIUCHI, 1971) was also used.

Unidirectional sodium flux was occasionally measured in the short-circuited skins using ${ }^{22} \mathrm{Na}$. Radioactive tracer $(20 \mu \mathrm{Ci} / 0.8 \mathrm{ml})$ was added to the inside chamber when the outflux was measured (final concentration: $1.04 \mu \mathrm{Ci} / \mathrm{ml}$ ), while $2 \mu \mathrm{Ci} / 0.08 \mathrm{ml}$ was added to the outside solution for the influx measurement (final concentration: $0.10 \mu \mathrm{Ci} / \mathrm{ml}$ ). Samples $(4 \mathrm{ml})$ were removed from the solution of the opposite side every $15 \mathrm{~min}$ for radioactivity determination. Immediately after the removal of 'hot' Ringer's solution, the same amount of 'cold' Ringer's solution was added to the chamber to keep the volume of solution $(20 \mathrm{ml})$ constant. The radioactivity of the sample in a lucite test tube was counted in a well-type scintillation counter (Aloka Autowell Gamma System JDC-752). The fall in the activity due to dilution by sampling was arithmetically compensated.

\section{RESULTS}

\section{Effects of $\mathrm{Cd}$ concentration}

Effects of $\mathrm{Cd}$ at various concentrations on the potential difference (PD) of abdominal frog skin was preliminary examined in Cl-Ringer's solution by using the A-type apparatus. A small amount of concentrated $\mathrm{Cd}$ solution was applied to both sides of the skin. The change in osmolarity due to the addition of Cd was less than 1 percent. The higher the concentration of $\mathrm{Cd}$, the larger the increase in the PD in the range from $2 \mathrm{~mm}$ to $0.1 \mathrm{~mm} \mathrm{Cd}$. An example of effects of $\mathrm{Cd}$ at two concentrations is represented in Fig. 3.

Change in PD was not remarkable in most cases when $\mathrm{Cd}$ was applied in Cl-Ringer's solution. In order to exclude the effect on passive and probable active transport of $\mathrm{Cl}$ in frog skin, we replaced $\mathrm{Cl}$ with more impermeable $\mathrm{SO}_{4}$ in Ringer's solution in the following experiments.

\section{Effect of epidermal and dermal $C d$}

The difference between effects of epidermal (outside) and dermal (inside) application of $\mathrm{Cd}$ was examined in $\mathrm{SO}_{4}$-Ringer's solution. The solutions of both sides were renewed about one hour after the setup of the skin preparation. The 


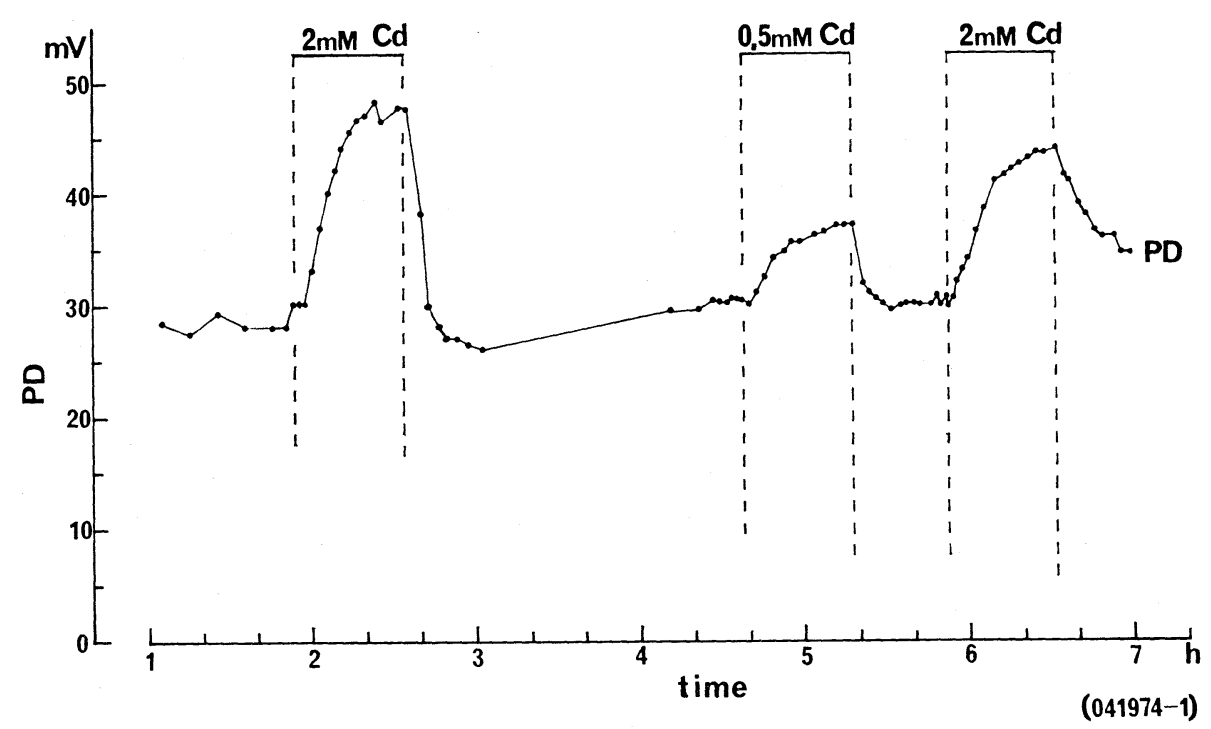

Fig. 3. Effects of concentration of $\mathrm{Cd}$ on the potential difference (PD) of frog skin. Two mM Cd was applied to both sides of the preparation.

skin under the open-circuited conditions was allowed to equilibrate for at least two hours before application of Cd. Both short circuit current (SCC) and PD of the skin were intermittently recorded. The concentration of $\mathrm{Cd}$ was fixed at $2 \mathrm{~mm}$ which exerted the maximum effect on the PD. Figure 4 represents a typical example of the effect of Cd given to either dermal or epidermal solution (A-type

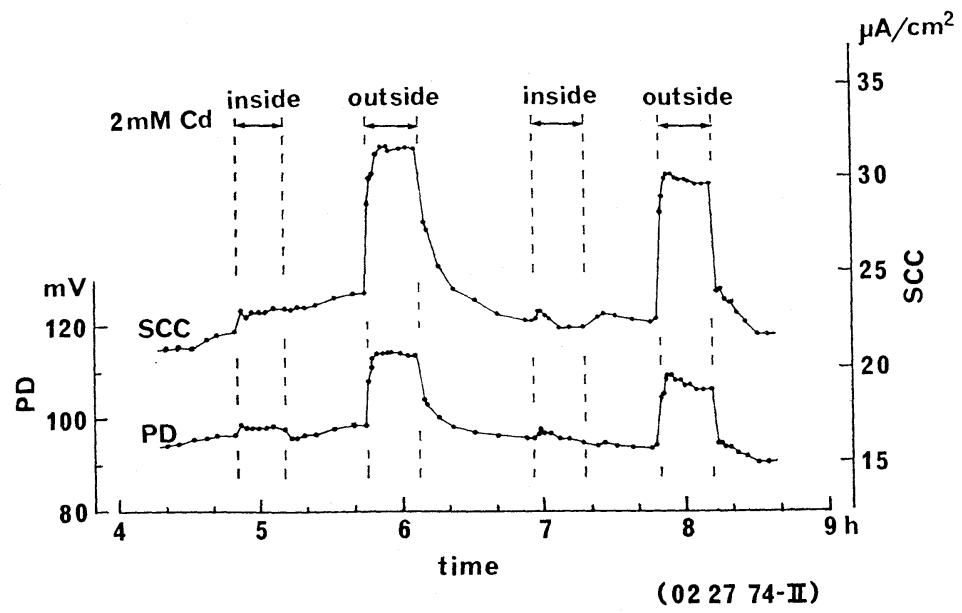

Fig. 4. Effects of epidermal (outside) and dermal (inside) $2 \mathrm{~mm} \mathrm{Cd}$ on the short circuit current (SCC) and the potential difference (PD) of frog skin. 
experiment). Both SCC and PD were remarkably increased immediately after the application of Cd to the outside; SCC was increased to 136 and 135 percent of the control, and PD was also increased to 115 and 117 percent of the control in this particular case. On the contrary, application to the inside brought about no remarkable changes in SCC and PD (less than 2 percent in this case).

\section{Classification of $C d$ effects}

In most preparations, both SCC and PD were increased throughout the period of $\mathrm{Cd}$ application. However, more complicated time courses of changes in SCC and PD were sometimes observed. Figure 5 illustrates an example which shows

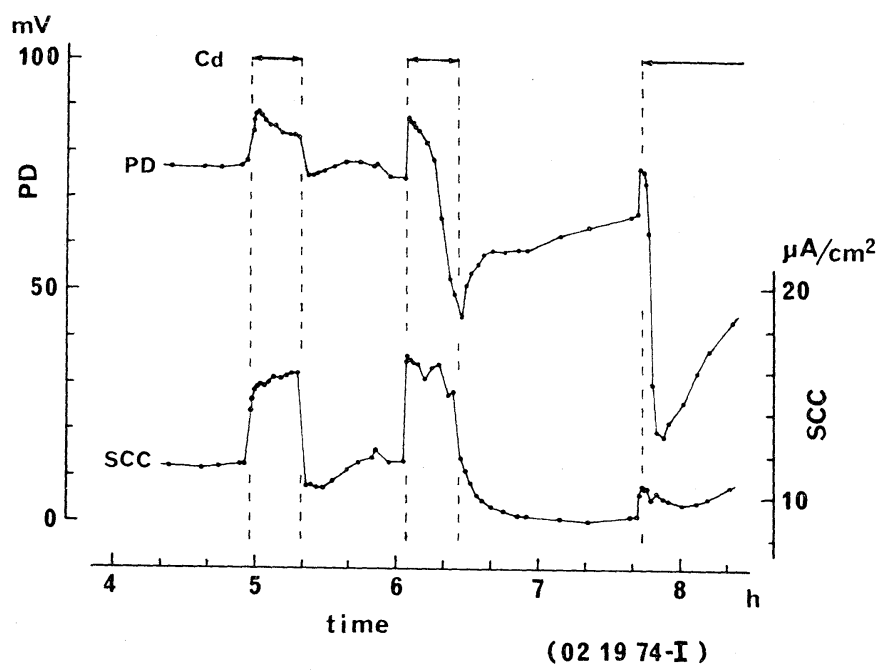

Fig. 5. Three kinds of patterns on the changes in the short circuit current (SCC) and the potential difference (PD) induced by successive applications of epidermal $\mathrm{Cd}(2 \mathrm{mM})$.

different time courses of the changes induced by successive epidermal application of $\mathrm{Cd}$ at $2 \mathrm{~mm}$ in a single skin preparation.

We classified the responses of SCC and PD to Cd into three types: (I) a simple increase in SCC and/or PD during the presence of Cd, (II) a decrease followed by an increase in SCC and/or PD except initial short period of small increase, and (III) a decrease in SCC and/or PD except initial short period of small increase.

\section{Cd effect on Na flux}

In order to elucidate mechanisms underlying above stated complicated responses of frog skins, $\mathrm{Na}$ flux was measured in following conditions; the concentration of $\mathrm{Cd}$ : $2 \mathrm{~mm}$, side of application of $\mathrm{Cd}$ : epidermal side (outside), solu- 
tion: $\mathrm{SO}_{4}$-Ringer's solution. Cd-induced changes in electromotive force of $\mathrm{Na}\left(E_{\mathrm{Na}}\right)$, resistance to the active $\mathrm{Na}$ current $\left(R_{\mathrm{Na}}\right)$, and resistance to the passive ions $\left(R_{\Sigma}\right)$ were compared with those in $\mathrm{PD}, \mathrm{SCC}$, and resistance of skin $\left(R_{M}\right)$. $E_{\mathrm{Na}}, R_{\mathrm{Na}}$, and $R_{\Sigma}$ were calculated by using the following equations: $E_{\mathrm{Na}}=(R T / F)$ $\ln (\mathrm{Na}$ influx/ $\mathrm{Na}$ outflux $), R_{\mathrm{Na}}=E_{\mathrm{Na}} / \mathrm{SCC}$, and $R_{M}=R_{\Sigma} \cdot R_{\mathrm{Na}} /\left(R_{\Sigma}+R_{\mathrm{Na}}\right)$, respectively. As the unidirectional flux of $\mathrm{Na}$ was determined in the present experiment, the $\mathrm{Na}$ flux in the opposite direction was calculated from the equation: SCC(unidirectional flux). Both influx and outflux were increased to similar extents by epidermal application of $\mathrm{Cd}$ in the preliminary experiment of $\mathrm{Na}$ flux determination. In order to minimize the error in calculating $E_{\mathrm{Na}}$, influx was obtained from the difference between $\mathrm{SCC}$ and $\mathrm{Na}$ outflux. $\mathrm{Na}$ was considered to be a sole ionic species responsible for the $\mathrm{SCC}$ because transport of anion $\left(\mathrm{SO}_{4}\right)$ might be little affected by $\mathrm{Cd}$ because of its low permeability.

$E_{\mathrm{Na}}, R_{\mathrm{Na}}$, and $R_{\Sigma}$ before and after application of $\mathrm{Cd}$ were calculated by determining $\mathrm{Na}$ flux in the cases of Fig. $6 \mathrm{~A}, \mathrm{~B}$ and $\mathrm{C}$ which were the typical examples of Type I, II, and III, respectively. ${ }^{22} \mathrm{Na}$ was injected to the dermal side one hour before the application of Cd. Sampling was started after $30 \mathrm{~min}$ of ${ }^{22} \mathrm{Na}$ introduction in order to equilibrate radioactive tracer in the frog skin. The data of $\mathrm{Na}$ determination during initial 10 to $15 \mathrm{~min}$ of $\mathrm{Cd}$ application were also discarded because the equilibrium state in the skin might not be attained during this period.

Table 1 summarizes the effects of $\mathrm{Cd}$ on the characteristics of the frog skin. The data in the upper, middle, and lower sections of Table 1 were obtained from the experiments in Fig. 6A, B, and C, respectively. All the data in Table 1 are

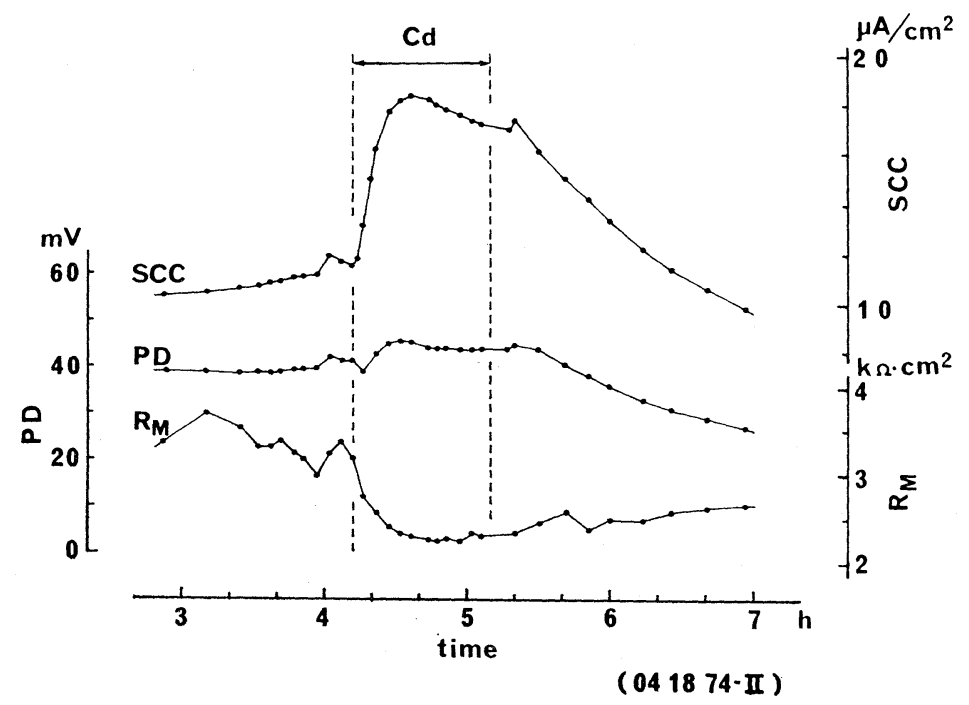




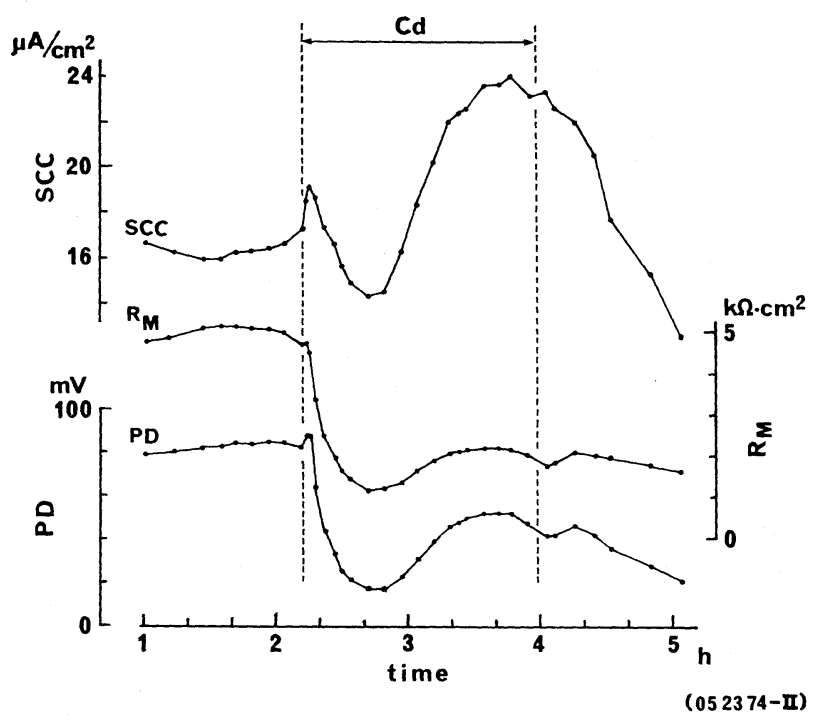

B

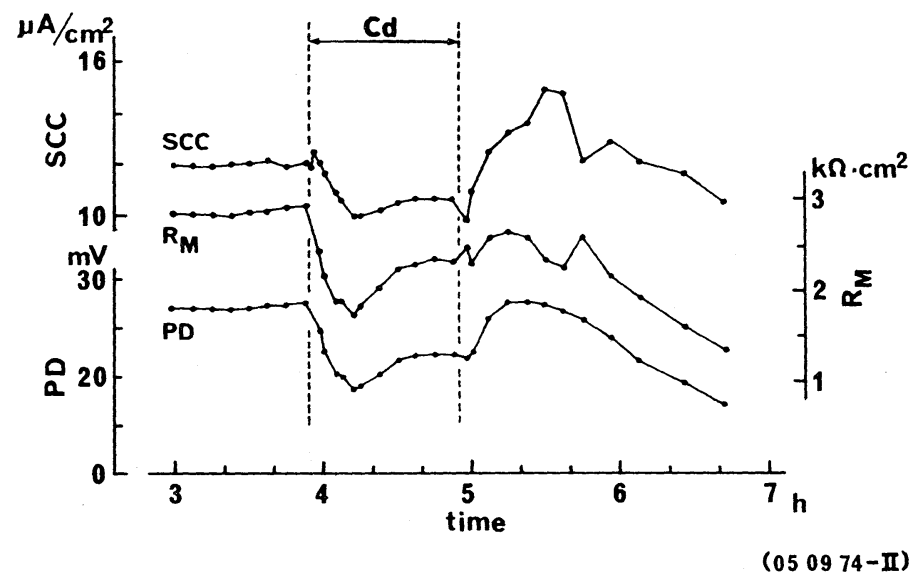

C

Fig. 6. Three typical examples of the effects of $\mathrm{Cd}$ on the short circuit current (SCC), the potential difference $(\mathrm{PD})$, and the skin resistance $\left(R_{M}\right)$. Na fluxes were determined every $15 \mathrm{~min}$ in these preparations. A: (Type I) increase in SCC during the application of $\mathrm{Cd}(1 \mathrm{hr})$. B: (Type II) decrease in SCC at the early stage (30 min after Cd application) followed by increase at the later stage $(1 \mathrm{hr})$. C: (Type III) decrease in SCC (1 hr).

expressed as the means of the respective data throughout the period mentioned in parentheses at the item of experimental conditions.

A. Analysis of Type I response. In the experiment of Fig. 6A (a typical 


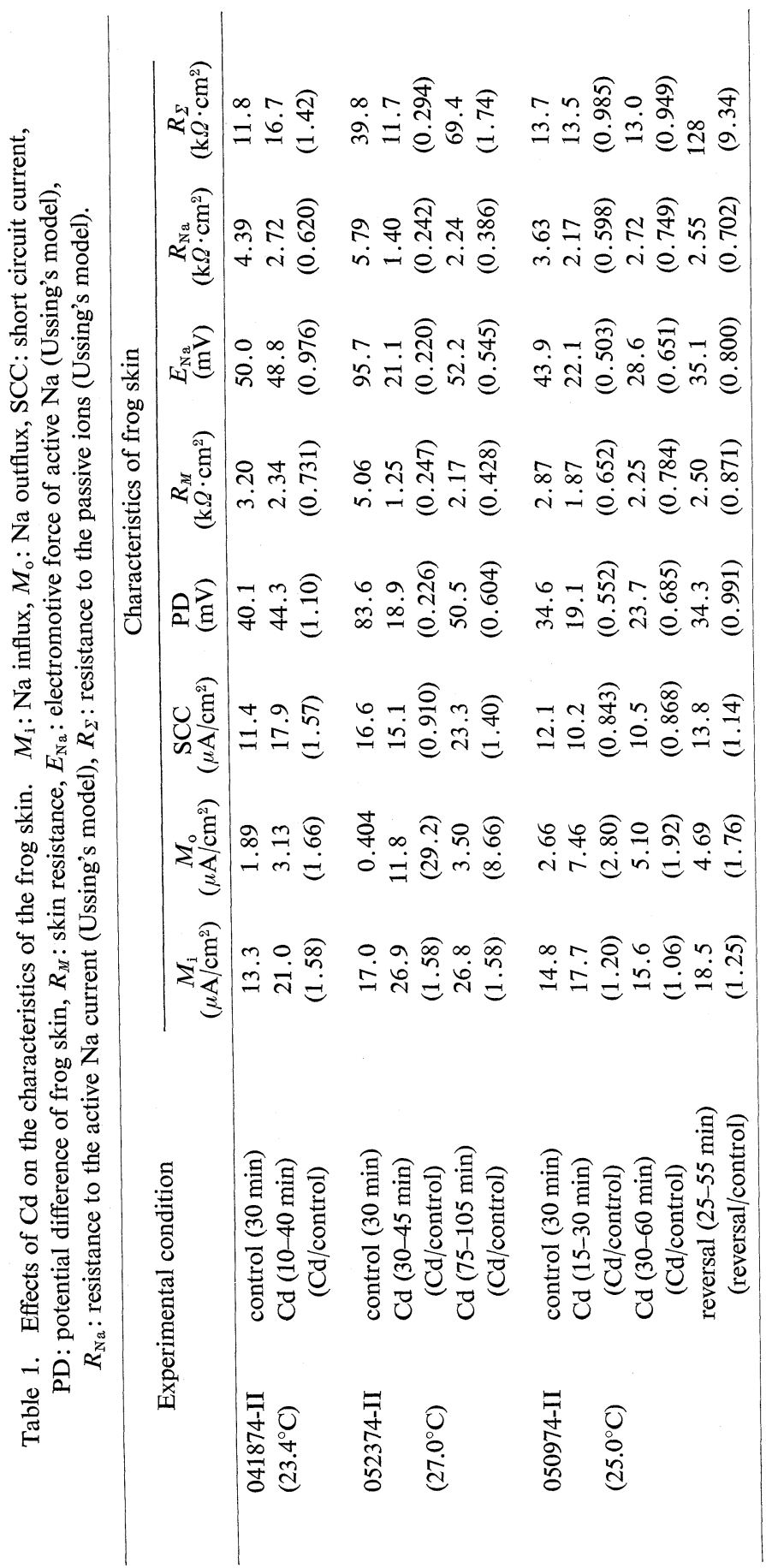


example of Type I group), SCC was greatly increased immediately after Cd application, and reached maximum after about $20 \mathrm{~min}$. Cd also induced a slight increase in $\mathrm{PD}$ which attained maximum about $20 \mathrm{~min}$ after $\mathrm{Cd}$ application. On the contrary, $R_{M}$ was remarkably decreased during $\mathrm{Cd}$ application.

The Cd-induced increase in SCC in Fig. 6A seems to be explained by the remarkable decrease in $R_{\mathrm{Na}}(62.0 \%$ of the control) accompanied by little change in $E_{\mathrm{Na}}(97.6 \%)$. (Note that $\left.\mathrm{SCC}=E_{\mathrm{Na}} / R_{\mathrm{Na}}.\right) \quad$ Although the rates of decrease in $R_{M}(73.1 \%)$ and $R_{\mathrm{Na}}(62.0 \%)$ were almost the same, $R_{\Sigma}$ seemed to be increased $(142 \%)$. According to Ussing's model for $E_{\mathrm{Na}}, R_{\mathrm{Na}}$, and $R_{\Sigma}$, PD is calculated by using the following equation: $\mathrm{PD}=E_{\mathrm{Na}} \cdot R_{\Sigma} /\left(R_{\mathrm{Na}}+R_{\Sigma}\right)$. Therefore, PD increase in Fig. $6 \mathrm{~A}$ might be explained by $R_{\mathrm{Na}}$ decrease, no change in $E_{\mathrm{Na}}$, and an increase in $R_{\Sigma}$. Good coincidence between the experimental and calculated values of the ratios of $\mathrm{PD}_{\mathrm{Cd}} / \mathrm{PD}_{\text {control }}$ was obtained, the former being 1.10 and the latter 1.14, respectively. Calculation of $\mathrm{PD}_{\mathrm{Cd}} / \mathrm{PD}_{\text {control }}$ was made by using the following equation:

$$
\begin{aligned}
\mathrm{PD}_{\mathrm{Cd}} / \mathrm{PD}_{\text {control }}= & \left(E_{\mathrm{Na}, \mathrm{Cd}}\right) /\left(E_{\mathrm{Na}, \text { control } 1}\right) \cdot\left(R_{\Sigma, \mathrm{Cd}}\right) /\left(R_{\Sigma, \text { control }}\right) \cdot \\
& \left(R_{\mathrm{Na}, \text { control }}+R_{\Sigma, \text { contro } 1}\right) /\left(R_{\mathrm{Na}, \mathrm{Cd}}+R_{\Sigma, \mathrm{Cd}}\right) .
\end{aligned}
$$

It is noteworthy that the above equation for the calculation of PD ratio does not include the experimental PD values at all.

B. Analysis of Type II response. Figure 6B shows a typical example of Type II response in regard to the time course of SCC. Cd brought about a small initial increase in SCC (112\% of the control) for a short period of $10 \mathrm{~min}$, which was followed by a decrease at a relatively early stage (the minimum value, $83 \%$, was attained at $30 \mathrm{~min}$ ) and the second increase appeared in a later stage (90 $\mathrm{min}$ for the maximum value, $139 \%$ ).

$\mathrm{Cd}$ induced a small initial increase in PD $(110 \%$ of the control) which was followed by a remarkable decrease (30 min for the minimum value, $21 \%$ ) and a slight slow recovery ( $80 \mathrm{~min}$ for the maximum value, $65 \%$ ).

The remarkable decrease in $R_{M}$ in the early stage (30 min for the minimum value, $22 \%$ ) and the slight recovery ( $80 \mathrm{~min}$ for the maximum value, $42 \%$ ) in the later stage were observed during $\mathrm{Cd}$ application.

The Cd-induced initial changes in the characteristics of the skin could not be analyzed by determining $\mathrm{Na}$ flux, because these initial changes disappeared within $10 \mathrm{~min}$ though new equilibrium of $\mathrm{Na}$ in the skin took at least $15 \mathrm{~min}$ after the application of $\mathrm{Cd}$.

The Cd-induced decrease in SCC in the early stage can be explained by the difference in the extents of decreases in both $E_{\mathrm{Na}}(22.0 \%)$ and $R_{\mathrm{Na}}(24.2 \%)$.

The experimental and calculated ratios of $\mathrm{PD}_{\mathrm{Cd}}$ to $\mathrm{PD}_{\text {contro1 }}$ in the early stage were in good agreement with each other: $22.6 \%$ and $22.5 \%$, respectively.

As $R_{\Sigma}$ was always much larger than $R_{\mathrm{Na}}, R_{M}$ was mainly determined by $R_{\mathrm{Na}}$. Therefore, the remarkable decrease in $R_{M}$ in the early stage is due to the remarkable decrease in $R_{\mathrm{Na}}$. 
The increase in SCC in the later stage of Cd effect can be explained by the difference in the extents of the recovery of $E_{\mathrm{Na}}(22.0 \rightarrow 54.5 \%)$ and $R_{\mathrm{Na}}(24.2 \rightarrow$ $38.6 \%$ ), respectively.

The experimental and calculated ratios of $\mathrm{PD}_{\mathrm{Cd}}$ to $\mathrm{PD}_{\text {control }}$ in the later stage were in good agreement with each other: $60.4 \%$ and $60.3 \%$, respectively.

Slight recovery of $R_{M}(24.7 \rightarrow 42.8 \%)$ is caused by that of $R_{\mathrm{Na}}(24.2 \rightarrow 38.6 \%)$.

C. Analysis of Type III response. Figure 6C shows a typical example of Type III response. As in the case of Fig. 6B, Cd induced a small initial increase in SCC (105\% of the control); however, SCC was decreased during the whole period of $\mathrm{Cd}$ application though very slight recovery was observed. The time courses of PD and $R_{M}$ during the effect of Cd were similar to that of SCC. The good recovery was observed after washing with $\mathrm{SO}_{4}$-Ringer's solution.

The mechanism of Cd-induced changes in SCC, PD, and $R_{M}$ in the early and the later stages in Fig. $6 \mathrm{C}$ seems to be essentially the same, with respect to $E_{\mathrm{Na}}$ and $R_{\mathrm{Na}}$, as that in Fig. $6 \mathrm{~B}$ except for the extent of recovery during $\mathrm{Cd}$ application which is very slight in Fig. 6C as compared with that in Fig. 6B. There is a good agreement in experimental and calculated values of the ratio $\left(\mathrm{PD}_{\mathrm{Cd}} / \mathrm{PD}_{\text {control }}\right)$ : 55.2 and $54.8 \%$ in the early stage, 68.5 and $68.1 \%$ in the later stage, respectively.

\section{Analyses of SCC and PD in terms of $E_{N a}$ and $R_{N a}$}

The results of 28 cases of Na flux determination are summarized in Figs. 7 and 8. Among the total experiments, 17 cases $(61 \%$ ) belong to Type I (an increase in SCC during Cd application), 2 cases ( $7 \%$ ) to Type II (an early decrease followed by a later increase in SCC), and 9 cases (32\%) to Type III (a decrease in SCC during Cd application). All data in these figures are standardized by control data $\left(\right.$ datum $_{\mathrm{Cd}} /$ datum $\left._{\text {control }}\right)$.

Figure 7A shows the relationship between $R_{\mathrm{Na}}$ and SCC. The dots in the quadrant IV belong to Type I. There is a rough linear relationship between them; the larger the SCC, the smaller the $R_{\mathrm{Na}}$. The arrows indicate the transition from the state of the early stage to that of the later stage during $\mathrm{Cd}$ application.

The dots in the quadrants II and III belong to Type III. The Cd induced SCC decrease was accompanied with $R_{\mathrm{Na}}$ decrease in the most cases of Type III group. SCC is roughly proportional to $R_{\mathrm{Na}}$.

There are two dots which translocate from the quadrant III to the quadrant IV as indicated by arrows. These cases belong to Type II group.

Figure $7 \mathrm{~B}$ represents the relation between $E_{\mathrm{Na}}$ and SCC. No appreciable change in $E_{\mathrm{Na}}$ is observed despite significant increases in SCC in the most cases of Type I group. There is a rough linear relationship between $E_{\mathrm{Na}}$ and SCC in the most cases of Type III group.

The relations of $R_{\mathrm{Na}}$ and $E_{\mathrm{Na}}$ with respect to PD are illustrated in Fig. 8A and $\mathrm{B}$, respectively. No appreciable correlation between $R_{\mathrm{Na}}$ and PD is observed; however, clear correlation is demonstrated between $E_{\mathrm{Na}}$ and PD. 


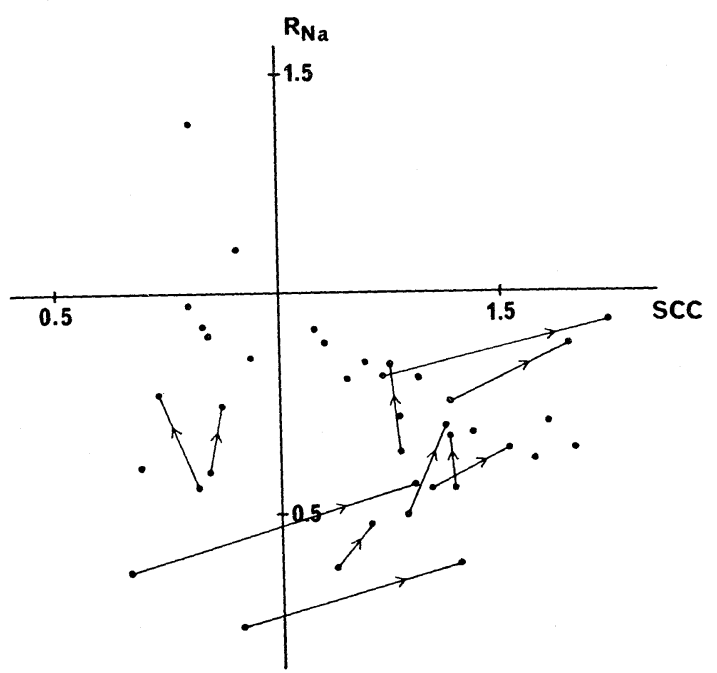

A

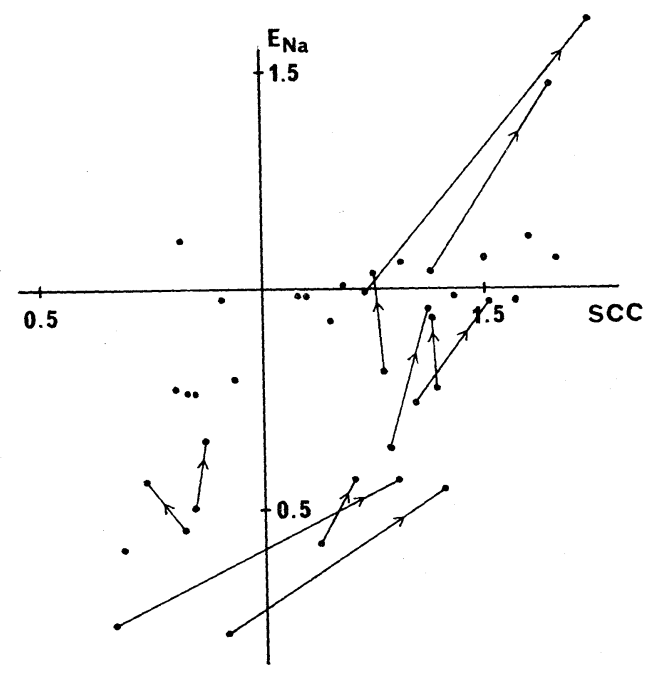

B

Fig. 7. Relationship between $R_{\mathrm{Na}}$ and SCC (A), and that between $E_{\mathrm{Na}}$ and SCC (B) after epidermal $2 \mathrm{~mm} \mathrm{Cd}$. All data are standardized. Arrows indicate the data obtained at the early stage and the later stage during Cd application.

\section{DISCUSSION}

The mechanism of active transport of $\mathrm{Na}$ was studied by applying $\mathrm{Cd}$ to frog skin in simplified system, i.e., under a short-circuited condition in $\mathrm{SO}_{4}$-Ringer's solution. The reasons why the present experiments were carried out in $\mathrm{SO}_{4}$ - 


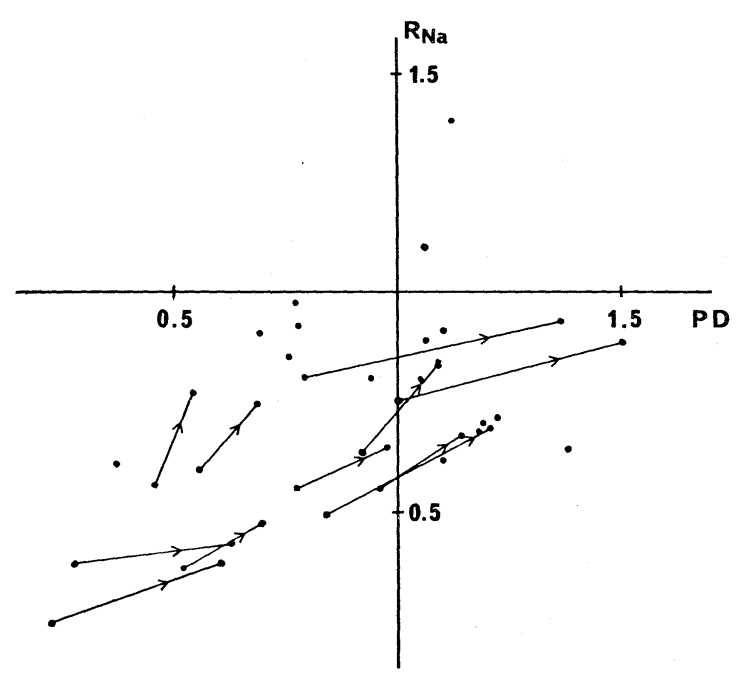

A

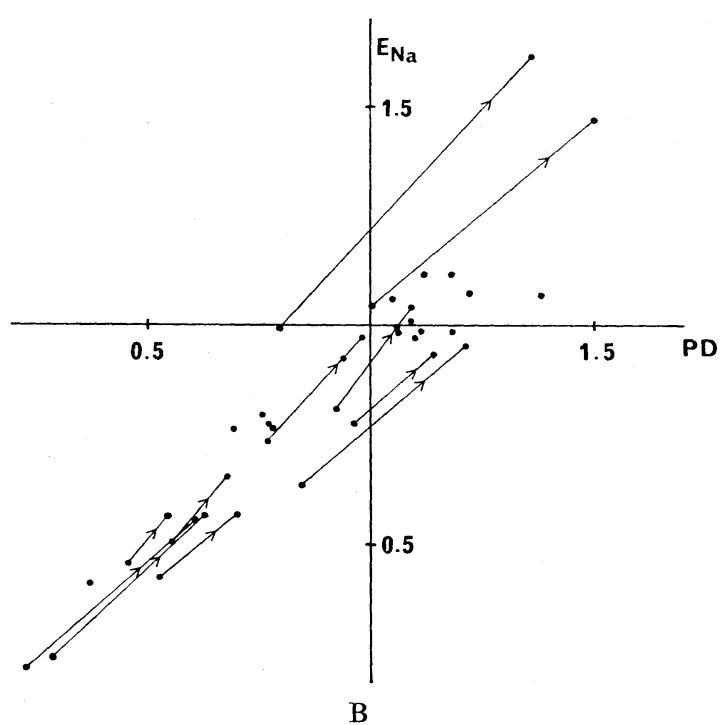

Fig. 8. Relationship between $R_{\mathrm{Na}}$ and PD (A), and that between $E_{\mathrm{Na}}$ and PD (B) after epidermal $2 \mathrm{~mm}$ Cd. All data are standardized. Arrows indicate the data obtained at the early stage and the later stage during $\mathrm{Cd}$ application.

Ringer's solution instead of Cl-Ringer's solution were as follows; 1) Our preliminary experiments on $\mathrm{Cd}$ effects on the frog skin during one year revealed that change in SCC and/or PD was not remarkable in most cases of Cl-Ringer's solution. This finding seemed to be in accord with those of other investigators'. 
2) The $\mathrm{Cl}$ transport might not be passive only; there is a high possibility of the active $\mathrm{Cl}$ transport (ZADUNAISKY et al., 1963; UsSING and ZERAHN, 1951; MARTIN and CURRAN, 1966); therefore, we used less a permeable anion, $\mathrm{SO}_{4}$, (KoEFOEDJOHNSEN and UsSING, 1958; Hagrwara et al., 1971) instead of $\mathrm{Cl}$ in Ringer's solution.

No consistent results were obtained for the direction of Cd-induced change in SCC by other investigators; in other words, both increase and decrease in SCC were reported by them. We have classified the time courses of SCC after Cd application into three types. As previously described, in approximately twothirds of cases (Type I), SCC was sustained at an increased level, while in the rest of cases (Types II and III), SCC changed in a triphasic manner (an initial increase, a successive decrease in the early stage and an increase in the later stage). The above stated classification suggests that the time course of Cd-induced change in SCC was composed of at least three exponential curves whose time constants and latencies after application of $\mathrm{Cd}$ were different from each other. The first positive component increases immediately after the application of $\mathrm{Cd}$, and reaches maximum within about $5 \mathrm{~min}$. The second negative component begins to decrease about 5-10 min after $\mathrm{Cd}$, and reaches minimum within 20-30 min. The third positive component starts to increase 20-30 min after $\mathrm{Cd}$, and attains maximum within about $1 \mathrm{hr}$.

The three different "phenotypes" (Types I, II, and III) in regard to time course of SCC, therefore, seem to be consistently explained by a sequence of three components or processes. The appearance of each phenotype depends on the predominance of one of three processes over the others. Thus, if the first process prevails against the others throughout, Type I will appear. The early stages of Type II and III (the decrease in SCC) are due to the predominance of the second process over the first one. The large predominance of the third process will explain the later stage of Type II (the increase in SCC).

The possible mechanisms of these three processes will be tentatively assumed. The first process is due to decrease in the membrane resistance of the outer barrier within epidermis. This assumption is supported by the following experimental facts: 1) a decrease in calculated $R_{\mathrm{Na}}, 2$ ) a decrease in total skin resistance, 3 ) a decrease in skin resistance of epidermal side ( $c f$. our next paper), and 4) ineffectiveness of dermally applied $\mathrm{Cd}$.

The second process is supposed to be an inhibitory effect of $\mathrm{Cd}$ which invades the epidermis and lowers the activity of $\mathrm{Na}, \mathrm{K}$-ATPase. This assumption is supported by the experimental facts: 1) a decrease in calculated $E_{\mathrm{Na}}, 2$ ) histochemical verification of $\mathrm{Cd}$ in epidermis (no $\mathrm{Cd}$ existence in epidermis when $\mathrm{Cd}$ was applied dermally) (unpublished observation), and 3) a decrease in Na, K-ATPase activity over $10^{-6} \mathrm{M} \mathrm{Cd}$ (unpublished data).

The third process is phenomenologically due to the increase in $E_{\mathrm{Na}}$ or the recovery in the later stage preceded by $E_{\mathrm{Na}}$ decrease in the early stage. However, 
the underlying mechanism is still unclear. A few assumptions may be considered as the responsible factors as 1) an increase in $\mathrm{Na}$ concentration in the epidermal cells, 2) disinhibition of Na,K-ATPase which is once inhibited by $\mathrm{Cd}$, and 3 ) changes in the morphological or functional bindings between epidermal cells, etc.

Cd increases the total skin resistance $\left(R_{M}\right)$ in Cl-Ringer's solution (BANKS, 1974; BorghGraEF et al., 1971), whereas, $R_{M}$ is clearly decreased by $\mathrm{Cd}$ in $\mathrm{SO}_{4}$ Ringer's solution in our present study. This result agrees with that of Banks. $\mathrm{As} \mathrm{Cl}$ is considered to be a main ionic species for passive transport in Cl-Ringer's solution on frog skin, $\mathrm{Cd}$ is supposed to narrow the passive channel of the skin. This assumption is strongly supported by our observation that $R_{\Sigma}$ (the resistance to the passive ions) was increased several times by $\mathrm{Cd}$ in some cases ( $c f$. Table 1 ). The electronmicroscopic study on whether intercellular space in the epidermis would actually be reduced will be reported elsewhere. The Cd-induced decrease in $R_{M}$ in spite of an increase in $R_{\Sigma}$ in $\mathrm{SO}_{4}$-Ringer's solution is thus explained by the remarkable decrease in $R_{\mathrm{Na}}$ which is brought about as a result of the decrease in the resistance of epidermal cells.

We have succeeded in demonstrating the clear difference between the effects of epidermal and dermal $\mathrm{Cd}$. As shown in Fig. 4, dermal application of $\mathrm{Cd}$ at the same concentration as that applied to the epidermal side and at the same period does not affect SCC at all. This difference might be explained by the histochemical observation that dermally applied $\mathrm{Cd}$ does not reach the epidermis (unpublished observation). The $\mathrm{Cd}$ blockade in dermis might be due to the capture of $\mathrm{Cd}$ by the large amount of $\mathrm{Ca}$ in dermis (especially in the sieve layer) (TAYLOR et al., 1966; HAYASHI et al., 1977).

$\mathrm{Ca}$ has been known as a competitive antagonist with $\mathrm{Cd}$ in the contractility of the cardiac muscle (HAYASHI and HorIUCHI, 1971). Ca has been also shown to counteract with $\mathrm{Cd}$ in the acetylcholine releasing mechanism from the peripheral end of vagal nerve (HAYASHI and TAKAYAMA, 1977). In the present study with frog skin, we observed approximately $35 \%$ increase in SCC, $10 \%$ decrease in $R_{M}$ in Ca-free EDTA Ringer's solution, while application of $2 \mathrm{~mm} \mathrm{Ca}$ brought about $20 \%$ decrease in SCC. These results closely resemble those of HillyARD and GoNICK (1976) and CURRAN and GiLl (1962). From the above results, however, we could not conclude at the present moment that $\mathrm{Cd}$ and $\mathrm{Ca}$ counteract with each other though these two ionic species have an opposite effects on SCC and $R_{M}$.

The effects of $\mathrm{Cd}$ on the frog skin are interesting not only from the standpoint of general physiology, but also from that of pathophysiology. Some type of renal hypertension has been caused by $\mathrm{Cd}$ as the result of increased active $\mathrm{Na}$ transport (VANDER, 1962; SCHROEDER, 1964).

This work was partly supported by a grant from the Ministry of Education, Science and Culture of Japan. 


\section{REFERENCES}

ARITA, A. and HAYASHI, H. (1973) High input impedance and high CMR biological amplifier composed of operational amplifiers. Jap. J. Med. Electron., 11: 124-127.

BANKS, R. O. (1974) Cadmium stimulation and cadmium-cystein inhibition of active transport by the frog skin. Physiologist, 17: 175.

Borghgraef, R., Stymans, A., and Driessche, W. V. (1971) The action of divalent cations on the electrical resistance of frog skin. Arch. Int. Physiol. Biochim., 79: 171-173.

Curran, P. F. and Gill, J. R., Jr. (1962) The effect of calcium on sodium transport by frog skin. J. Gen. Physiol., 45: 625-641.

Ferreira, K. T. G. (1970) The effect of $\mathrm{Cu}^{2+}$ on isolated frog skin. Biochim. Biophys. Acta, 203: $555-567$.

Hagiwara, S., TOYAMA, K., and HAYASHI, H. (1971) Mechanisms of anion and cation permeations in the resting membrane of a barnacle muscle fiber. J. Gen. Physiol., 57: 408-434.

HAYASH, H. and Horiuchi, E. (1971) Effect of cadmium ion on the bullfrog heart. J. Physiol. Soc. Jap., 33: 368-369.

Hayashi, H., Arita, A., Takada, M., and Takayama, K. (1974) Cd induced enhancement of active sodium transport in frog skin. J. Physiol. Soc. Jap., 36: 354.

Hayashi, H., TAKada, M., and Watabe, T. (1977) Distribution of Ca and P in a frog skin: An analytical study of elements with electron probe X-ray microanalyzer. J. Saitama Med. Sch., 4: (in press).

HAYASH, H. and TAKAYAMA, K. (1977) Cd induced suppression on the effect of cardiac efferent stimulation. J. Toxic. Sci., 2: 27-28.

Hillyard, S. D. and Gonick, H.C. (1976) Effects of $\mathrm{Cd}^{2+}$ on short-circuit current across epithelial membranes. J. Membr. Biol., 26: 109-119.

Koffoed-Johnsen, V. and Ussing, H. H. (1958) The nature of the frog skin potential. Acta Physiol. Scand., 42: 298-308.

Martin, D. W. and Curran, P.F. (1966) Reversed potentials in isolated frog skin. II. Active transport of chloride. J. Cell. Physiol., 67: 367-374.

Martinez-Palomo, A., ErliJ, D., and Bracho, H. (1971) Localization of permeability barriers in the frog skin epithelium. J. Cell Biol., 50: 277-287.

SCHroeder, H. A. (1964) Cadmium hypertension in rats. Am. J. Physiol., 207: 62-66.

STymans, A. and Borghgraef, R. (1969) The action of Cd on the Na-transport in the frog skin. Arch. Int. Physiol. Biochim., 77: 334-335.

TAYlor, R. E., Jr., TAYLOR, H. C., and BARKER, S. B. (1966) Chemical and morphological studies on inorganic phosphate deposits in Rana catesbeiana skin. J. Exp. Zool., 161: 271-286.

Ussing, H. H. (1949) The distinction by means of tracers between active transport and diffusion. Acta Physiol. Scand., 19: 43-56.

Ussing, H. H. and ZerahN, K. (1951) Active transport of sodium as the source of electric current in the short-circuited isolated frog skin. Acta Physiol. Scand., 23: 110-127.

VANDER, A. J. (1962) Effect of cadmium on renal tubular sodium transport. Am. J. Physiol., 203: $1-5$.

Zadunaisky, J. A., Candia, O. A., and Chiarandini, D. J. (1963) The origin of the shortcircuit current in the isolated skin of the South American frog Leptodactylus ocellatus. J. Gen. Physiol., 47: 393-402. 